\title{
Personality Trait Development Across the Transition to Retirement
}

\author{
Ted Schwaba ${ }^{1}$ \\ Wiebke Bleidorn $^{1}$ \\ ${ }^{1}$ University of California, Davis, United States
}

Correspondence concerning this article should be addressed to Ted Schwaba, Department of Psychology, University of California Davis, One Shields Avenue, Davis, CA 95616, United States. E-mail: tedschwaba@gmail.com

Please cite this preprint as:

Schwaba, T., \& Bleidorn, W. (2017). Personality Trait Development Across the Transition to Retirement. Journal of Personality and Social Psychology. 


\title{
Personality Trait Development Across the Transition to Retirement \\ Running head: PERSONALITY ACROSS RETIREMENT
}

\begin{abstract}
In this study, we examined trajectories of Big Five personality development in the five years before and after retirement. Our sample was composed of 690 retirees (ages 51-81) and a propensity-score matched comparison group of 532 non-retirees drawn from a nationally representative longitudinal study of the Netherlands. Participants contributed data across a maximum of six measurement waves over a period of seven years. In the month after retirement, participants experienced sudden increases in openness and agreeableness followed by gradual declines in these traits over the next five years. Emotional stability increased before and after retirement. The transition to retirement was not associated with changes in conscientiousness or extraversion. Further, we found significant individual differences in development across the transition to retirement for each personality trait but could not identify any moderators that accounted for these individual differences. These results contribute to our understanding of personality development in older adulthood as well as the temporal dynamics of personality change in response to major life events.

Keywords: Retirement, Personality Development, Late Adulthood, Big Five
\end{abstract}


People spend their lives navigating a sequence of events in the domains of work and love. A vast number of theories have been put forth to explain how these life events affect lifespan personality development (e.g. Baltes, 1987; Bleidorn, 2015; Carstensen, Fung, \& Charles, 2003; Caspi \& Roberts, 1999; Digman, 1997; Elder, 1995; Erikson, 1959; Roberts, Wood, \& Caspi, 2008; Bleidorn, Hopwood, \& Lucas, 2017; Specht et al., 2014). Most research on life events and personality development has focused on life events that normatively occur in early adulthood, such as marriage, parenthood, or graduation from school (e.g., Bleidorn, 2012, Neyer \& Lehnart, 2007; van Scheppingen et al., 2016). In contrast, research on life events and personality development in middle and late adulthood is relatively scarce. Because of this, we have little understanding of how life events affect personality development in middle and late adulthood, and thus limited evidence by which to evaluate theories of personality development in middle adulthood and old age.

Retirement is a major life event in late midlife that affects a person’s behavior, identity, and goals (Erikson, 1959; Löckenhoff, Terracciano, \& Costa, 2009) and may play a critical role in adult personality development. To date, three longitudinal studies have investigated associations between retirement and Big Five personality change (Löckenhoff et al., 2009; Mroczek \& Spiro, 2003; Specht, Egloff, \& Schmukle, 2011). However, these studies have yielded conflicting results and each faced substantial methodological limitations. It is still largely unclear how personality develops across the transition to retirement.

In this study, we examine Big Five (John, Naumann, \& Soto, 2008) personality development in the five years before and after retirement using a large representative sample of the Netherlands that has provided up to six waves of personality data over a period of seven years. Specifically, we estimate trajectories that describe how people prepare for, react to, and 
adapt to retirement, and we compare these trajectories to the personality trajectories of a matched comparison group of individuals who did not retire during the study period. We then examine the extent to which retirees exhibit individual differences in personality development and explore a set of moderators that may explain these individual differences. Through these analyses, we expand upon previous research to gain a more complete understanding of how retirement is associated with change and continuity in personality traits.

\section{Personality Trait Development Across Middle and Late Adulthood}

Several studies have examined normative patterns of Big Five personality development across middle and old adulthood (Allemand, Zimprich, \& Hertzog, 2007; Allemand, Zimprich, \& Martin, 2008; Mueller et al., 2016; Schwaba \& Bleidorn, 2017; Specht et al., 2011; Wortman, Lucas, \& Donnellan, 2012; for a review see Bleidorn \& Hopwood, 2017). These studies have found that, across ages 50 to 80, emotional stability and agreeableness tend to increase, extraversion tends to remain stable, openness tends to decrease, and conscientiousness tends to initially increase and then decrease once participants reach about age 75. However, not all people develop according to these normative trends. Across the lifespan, there are individual differences in personality development (Schwaba \& Bleidorn, 2017), which are attributable to both genetic and environmental factors (Bleidorn et al., 2009; Hopwood et al., 2011).

These developmental trends may be partially driven by life events that typically occur in middle and late adulthood, such as retirement, health issues, transitioning into assisted living, children moving out, or death of loved ones (Specht et al., 2011; Mroczek \& Spiro, 2003; Mueller et al., 2016). As people anticipate, experience, and adapt to these life events, they may change their social roles, status, and identity. These changes may drive personality development from the top down (Wood \& Roberts, 2005). Furthermore, major life events may have an 
enduring impact on peoples’ thoughts, feelings, and behavior, driving personality development from the bottom up (Roberts, 2017; Wrzus \& Roberts, 2017). These commonly experienced topdown and bottom-up influences may, to some extent, underlie the normative patterns of personality trait change in middle and late adulthood.

We currently know little about the impact of life events on personality development in middle and old age. For retirement in particular, few studies have examined whether and how personality traits change when people undergo this major transition (Löckenhoff et al., 2009; Mroczek \& Spiro, 2003; Specht et al., 2011).

\section{Retirement and Personality Trait Development}

Retirement is a major life event that may spur major changes in personality. Indeed, the transition into retirement impacts nearly every domain of life (Kim \& Moen, 2001; Osborne, 2012). Retirees gain hours of free time per day that must be reorganized and refilled. They must redefine their identity as they relinquish their work roles and assume new ones (Erikson, 1959). As retirees transition from paychecks to a pension, they must adapt to a new economic situation, and they must find new goals outside of the work domain (Fisher, 1993). Notably, many retirees face substantial uncertainty about how to adapt to each of these changes, as the transition to retirement comes with less clear behavioral and role expectations than other major life transitions (e.g. entering the workforce; Freund, Nikitin, \& Ritter, 2009).

Broad changes and uncertain expectations make retirement a fulcrum for personality development, according to Caspi and Moffitt’s (1993) paradoxical theory of personality coherence. This theory states that, when people enter novel situations with little information about how to behave adaptively, they use information in their environment to guide their behavior. In domains where there is a strong environmental press to act in a certain way, most 
people will change their behavior according to this press and will thus experience personality change. For example, retirees who spend increasing amounts of time with family and friends may face a strong environmental press to act in a more affiliative, communal way, promoting mean-level increases in agreeableness across the transition to retirement. However, not all people will experience this press: for those who retire into dysfunctional social environments, there may be a press to behave in a less agreeable manner, promoting individual differences in agreeableness development across the transition to retirement. Finally, if there is little press to behave in a certain way, retirees may adapt to these novel situations in ways consistent with their extant personality traits, promoting or even paradoxically enhancing personality continuity. In the following section, we outline specific environmental presses that may affect development in each of the Big Five traits.

\section{Retirement and Openness}

Changes in openness may begin before retirement occurs. As workers prepare to retire, they may begin to disengage with cognitively demanding aspects of their job. This disengagement may underlie decreases in openness that may occur in the months before retirement (Neiß \& Zacher, 2016; Schwaba et al., 2017). Immediately after retirement, retirees must decide how to spend their time previously spent at work. Some retirees may explore new leisure activities (Schwaba et al., 2017) and modify their social networks (Reitz, Zimmermann, Hutteman, Specht, \& Neyer, 2014). In this way, the period immediately after retirement may be marked by a brief increase in openness, with substantial individual differences in the magnitude of this change corresponding to the magnitude of exploration. As retirees adapt to their new situation, they may settle into their behavioral schedules, cease exploration, and resume agegraded decreases in openness. 


\section{Retirement and Conscientiousness}

Retirement may be associated with decreases in conscientiousness. Past research has found some evidence to suggest that commitment to work-related identities may drive agerelated increases in conscientiousness (Hudson \& Roberts, 2016; Lodi-Smith \& Roberts, 2007). As retirees divest from these work-related identities, they may decrease in conscientiousness, a pattern consistent with previous studies on personality change and retirement (Löckenhoff et al., 2009; Specht et al., 2011), which may partly explain the observed normative decreases in conscientiousness in older adulthood. As with openness, there may be individual differences in this change, as some retirees continue to invest in activities that require high conscientiousness, such as volunteering (Mike, Jackson, \& Oltmanns, 2014), while others divest from such commitments completely.

\section{Retirement and Extraversion}

Retirement may be particularly relevant for change in social dominance, a facet of the broader extraversion domain. Much of adulthood is characterized by increases in social dominance (Roberts, Walton, \& Viechtbauer, 2006), and these changes may be partly driven by age-graded career changes and the adoption of higher-status roles. Across the transition to retirement, people disengage from work roles, which may be associated with decreases in social dominance. Retirement has also been associated with decreases in the activity facet of extraversion (Löckenhoff et al., 2009), suggesting that people may often retire into a more sedentary, less social life. Others, however, may maintain or increase their levels of activity as they gain more free time to spend with their friends and family or to travel and exercise, which may also affect openness development (Stephan, Sutin, \& Terracciano, 2014; Zimmermann \& Neyer, 2011). 


\section{Retirement and Agreeableness}

Changes in roles and behavior may drive increases in agreeableness across the transition to retirement, consistent with age-graded norms (Roberts et al., 2006). Specifically, retirees may disengage from agentic career roles and adopt more communal roles as they increase their engagement in generative activities, such as volunteering or spending time with family and friends (McAdams, de St Aubin, \& Logan, 1993; Pundt, Wohrmann, Deller, \& Schultz, 2015). Retirees may also experience a behavioral press that rewards friendly compliance. While argumentativeness and competitiveness may offer benefits in a work context (such as when negotiating for a higher salary; Judge, Livingston, \& Hurst, 2012), retirees may instead be rewarded when they act in an agreeable manner, particularly when acting within family or community contexts. Such changes may promote increases in agreeableness across the transition to retirement.

\section{Retirement and Emotional Stability}

While all personality traits contain elements of affect, behavior, and cognition, emotional stability is the most affectively based of the Big Five (Wilt \& Revelle, 2015). Development in this trait across the transition to retirement may primarily depend on a person's emotional responses to the changes that come with retirement (Schwaba \& Bleidorn, 2017). Consistent with age-graded increases in emotional stability, most retirees may successfully navigate the uncertainty that comes with this life transition. However, a sizeable minority of older adults may experience difficulties making the transition to retirement and become less emotionally stable. These people may experience financial hardship or may have difficulty adapting to new roles and uncertain expectations (Freund et al., 2008; Kim \& Moen, 2001). Thus, there may be marked individual differences in the development of emotional stability after retirement. 


\section{Summary}

In summary, the changes that come with retirement may impact personality trait development in late adulthood. As retirees navigate the transition to retirement, they are faced with uncertain expectations in novel situations. The press of the environment may drive meanlevel changes in personality, if retirees experience and adapt to the press in similar ways, or individual differences in change, if retirees experience and adapt to the press in different ways. Furthermore, not all retirees will experience these presses. For these people, retirement may be a time of continuity in personality, even as their environment changes (Caspi \& Moffitt, 1993). To date, three studies have examined the ways in which people's personality traits change during the transition to retirement. These studies have yielded mixed and party conflicting results concerning the impact of retirement on personality-trait change

\section{Past Research on Retirement and Personality Development}

Three longitudinal studies to date have examined associations between retirement and personality trait change. These studies have not come to consistent conclusions about which traits are affected by this life event.

Mroczek \& Spiro (2003) provided an initial examination into retirement and personality change. Their sample was composed of American men born before 1945, most of whom were war veterans. They examined development in extraversion and neuroticism (low emotional stability) across five measurement occasions spaced a total of twelve years apart $(\mathrm{N}=1,663)$ and found no developmental differences between men who retired before the first measurement occasion and men who were not retired at the first measurement occasion (but may have retired during later waves).

Löckenhoff and colleagues (2009) examined cross-sectional and longitudinal associations 
between retirement and personality change. Their longitudinal sample was composed of 63 retirees and 304 non-retirees drawn from the Baltimore Longitudinal Study of Aging. Personality was measured twice across a 9-year interval. They found that participants low in conscientiousness were more likely to retire and that retirees increased more rapidly in agreeableness than non-retirees. At the facet level, they found that retirees decreased more rapidly than non-retirees in self-discipline (a facet of conscientiousness) and activity (a facet of extraversion). They also investigated associations between personality traits and retirementrelated variables. Retirees low in neuroticism and high in extraversion scored higher on retirement satisfaction, and retirees high in extraversion were more active in retirement and more likely to be involved in part-time work.

Most recently, Specht and colleagues (2011) examined longitudinal associations between life events and personality change using data from a nationally representative sample of German adults. They compared personality change across two measurement occasions spaced 4 years apart. After controlling for age and gender, retirees $(\mathrm{N}=693)$ tended to score higher on openness and decreased more rapidly in conscientiousness than non-retirees.

Together, these studies provide some evidence to suggest that retirees tend to decline in conscientiousness, particularly in the facet of self-discipline. Additionally, in none of these studies was retirement associated with the development of emotional stability. The evidence for change in other traits was inconsistent across studies. This mixed evidence may reflect differences in research design. To rigorously examine the role of retirement in personality development, several major methodological complexities must be considered (Bleidorn et al., 2016; Doss et al., 2009; Luhmann et al., 2014). We next turn to these methodological considerations. 


\section{Methodological Considerations in the Study of Retirement and Personality Trait Change}

In order to advance our understanding of personality development in the context of life events, researchers need to address several methodological issues. Here, we highlight four. Specifically, a better understanding of personality development in the context of retirement requires that researchers 1) account for the timing of retirement, 2) measure personality multiple times before and after retirement occurs, 3) account for pre-existing differences between those who do and do not retire, and 4) examine theoretically relevant moderators of individual differences before and after retirement. By addressing these complexities in the present study, we aim to improve upon and integrate past research on retirement and personality change.

First, to examine the shape of personality trajectories across the transition to retirement, longitudinal studies must measure the specific timing of retirement and consider development in relation to this date. Previous studies on retirement and personality trait change did not measure the date of retirement, which restricted these studies' analyses to between-group comparisons of the slopes of retirees and non-retirees. As the date of retirement is reported with increasing fidelity, individual trajectories can be examined with increasing nuance, and theoretical propositions can be evaluated more specifically.

Second, change in personality may occur before retirement as people anticipate and prepare for this transition. Studies that begin measuring personality after retirement cannot disentangle pre-retirement development from post-retirement development. To examine trait development across multiple stages of this process, longitudinal studies must measure personality at multiple occasions before and after retirement occurs. No study on retirement and personality to date has addressed this complexity.

Third, researchers must consider the development of a comparison group to better isolate 
the effects of retirement on personality development. Beyond potential effects of retirement, personality development may be driven by a host of other age-graded biological changes and environmental influences. When working with observational data, statistical techniques must be employed to rule out such confounding influences as best as possible. One common technique used for this purpose is propensity score matching. With propensity score matching, all participants in a sample who experienced an event are "matched" on observed variable scores to participants who did not experience the event but are otherwise similar in propensity to experience the event. Development can then be compared between these two groups (cf. van Scheppingen et al., 2016; Jackson, Thoemmes, Jonkmann, Lüdtke, \& Trautwein, 2012; Thoemmes \& Kim, 2011). Propensity-score matching can thus rule out many alternative explanations for development, such as historical effects (e.g. development due to the 2008 global recession), and age-graded development unrelated to the retirement transition.

Finally, people can differ in their preparation, reaction, and adaptation to retirement (Kim \& Moen, 2001). That is, there may be individual differences in personality development before, during, and after retirement (Schwaba \& Bleidorn, 2017). It is important to quantify this developmental heterogeneity and search for its determinants to better understand lifespan development at the level of the individual (Nesselroade \& Baltes, 1979, Roberts \& Mroczek, 2008). As mentioned above, Löckenhoff and colleagues (2009) have begun to address this issue by investigating attitudinal and behavioral correlates of personality change in retirement. However, their relatively small sample size prohibited strong conclusions regarding these effects. In this study, we extend this past research by examining a broad set of theoretically relevant moderator variables that may impact individuals’ personality trajectories during the transition to retirement. 


\section{Moderators of Personality Trait Development During the Transition to Retirement}

In the present study, we examined 13 theoretically relevant moderators that may account for individual differences in personality development during retirement: gender, age, health, financial situation, social integration, volunteering time, frequency of physical activity, and change in the other Big Five personality traits. These moderators may influence a person’s personality trait score at month of retirement as well as their personality development across the transition to retirement.

\section{Gender}

For this cohort of retirees, born in the mid 1900’s, work was a different experience for women and men (Han \& Moen, 1999). The transition from work to retirement may be similarly impacted by a person’s gender. Indeed, the extant literature suggests, but has not explicitly tested, that gender may affect personality development across the transition to retirement. Specifically, Mroczek \& Spiro (2003), who studied only men, did not find associations between retirement and extraversion change. In contrast, Löckenhoff and colleagues (2009), who studied both men and women, found that retirement was associated with a decrease in the activity facet of extraversion. This inter-study discrepancy may be due to a moderating effect of gender on personality development across the transition to retirement.

\section{Age}

The statutory retirement age in the Netherlands is currently 65 years, yet people retire at a wide range of ages. Some early retirees may view retirement as an opportunity to escape work and pursue new ventures (Siegrist, Wahrendorf, Von Dem Knesebeck, Jurges, \& Borsch-Supan, 2007) which may be associated with increases in extraversion and emotional stability before and after retirement. Others may be forced into early retirement by health problems, and these people 
may experience declines in extraversion and emotional stability across the transition to retirement (Mueller et al., 2017; Sutin et al., 2012). Others may retire much later than age 65. These late retirees may face unique challenges in compensating for age-related biological declines (Baltes et al., 1989). We examine both early retirement status (a categorical variable) and age at retirement (a continuous variable) as moderators of personality development.

\section{Financial Hardship}

Cross-sectional research suggests that economic resources have a significant impact on the well-being of retirees (Kim \& Moen, 1999). Given associations between well-being and emotional stability (Costa \& McCrae, 1980), it is likely that retirees who experience financial hardship may be more likely to decrease in emotional stability in retirement. The two constructs may also co-develop, such that increasing financial difficulty may be associated with decreasing emotional stability.

\section{Volunteering}

Volunteering offers an opportunity for retirees to spend their time generatively, giving back to the community (Son \& Wilson, 2011). As such, volunteering in retirement may be especially associated with the development of agreeableness. Volunteering is also an indicator of social engagement. Mike and colleagues (2014) demonstrated across two samples that workers high in conscientiousness tended to volunteer more in retirement. Hence, increases in volunteering behavior may be similarly associated with increases in conscientiousness.

\section{Subjective Health}

A substantial body of research has shown that late-life declines in health are associated with decreases in emotional stability, extraversion, agreeableness, openness, and conscientiousness (e.g. Mueller et al., 2016, 2017; Stephan et al., 2014; Sutin, Zonderman, 
Ferrucci, \& Terracciano, 2013), but the interplay between health and personality development has yet to be studied in the context of retirement. Because retirement itself may help preserve or even improve a person's subjective health (Coe \& Zamarro, 2011), associations between health change, retirement, and personality development may be complex.

\section{Physical Activity}

Retirement provides an opportunity for retirees to change their patterns of physical activity. Some retirees may become especially sedentary in retirement (Löckenhoff et al., 2009), while other retirees may spend their days hiking, biking, and walking. Past research has shown that physically active adults tend to score higher in openness, conscientiousness, extraversion, and agreeableness over time (Allen, Magee, Vella, \& Laborde, 2017). Further, increases in exercise may precipitate increases in openness (Stephan et al., 2014). Hence, we predicted that physical activity in retirement was positively related to changes in openness, conscientiousness, extraversion, and agreeableness.

\section{Social Connectedness}

Personality development across the transition to retirement may be contingent on a person’s social connectedness. Past research has suggested that personality change may be associated with changes in people’s social networks (Neyer \& Asendorpf, 2001, Zimmermann \& Neyer, 2013). Maintaining a strong social network across the transition to retirement may insulate a person from the disruptions in other life domains, promoting continuity in personality development. In contrast, those who become less socially connected in retirement, perhaps as a result of losing the social structure provided by work life, may be especially lonely and experience decreases in emotional stability and extraversion.

\section{Big Five Personality Traits}


Finally, trait development across the transition to retirement may be systematically related to the development in other Big Five traits. For example, past research has found that change in the traits of openness and extraversion is correlated, as well as change in the traits of agreeableness, conscientiousness, and neuroticism (Klimstra et al., 2014). Across the transition to retirement, we may find similar co-developmental patterns between Big Five traits.

\section{The Present Study}

We examined the trajectory of personality development across the transition to retirement using data from the Longitudinal Internet Studies for the Social Sciences (LISS) panel, a large, nationally representative sample of the Netherlands. Specifically, we sorted LISS participants into two groups: retirees ( $\mathrm{N}=690)$, who contributed up to six waves of yearly personality data, and a propensity score-matched group of non-retirees $(\mathrm{N}=532)$ who also contributed up to six waves of yearly personality data.

Within the retirement group, we estimated a series of multi-level models and used model comparison tests to identify the type and shape of change in each of the Big Five personality traits before, during, and after the transition to retirement (see Figure 1; cf. Bleidorn et al., 2016; Doss et al., 2009). These models ranged from an intercept-only model (1a), which suggests no change in personality across the transition to retirement, to a more complex model (2d), which suggests linear change in personality in the five years before retirement, an abrupt level change in personality corresponding to the date of retirement, and a different linear trajectory in the five years after retirement. Identifying the best-fitting model to the data allows us to estimate personality development in the average retiree as they prepare for and experience retirement.

To further investigate the effect of retirement on personality trait development, we compared the trajectories of retirees to the trajectories of the propensity-score-matched group of 
non-retirees. This allowed us to address potential alternative explanations, such as historical influences or age-graded influences on personality trait development. Finally, we estimated the extent to which participants exhibited individual differences in personality trait development before and after retirement. We then tested whether these individual differences in personality trait development were related to individual differences in broad set of theoretically relevant moderator variables.

\section{Method}

This study makes use of a publicly available de-identified archival dataset. It is thus exempt from Institutional Review Board approval. Other published work uses the same data, in part, as was used in the present research. These publications can be viewed at https://www.dataarchive.lissdata.nl/publications. None of these works analyze the development of personality traits across the transition to retirement, which is the central focus of this article

Data for this study came from the Longitudinal Internet Studies for the Social Sciences (LISS) panel, which has followed a representative sample of 21,894 members of the Dutch population from 2008 to 2016, 11,893 of which have provided Big Five personality data at one or more assessment waves. The panel is based on a true probability sample of households drawn from the population register (Scherpenzeel, Das, Ester, \& Kaczmirek, 2010). LISS participants complete yearly internet surveys on a variety of topics. Participants who did not have a computer or internet connection were provided with one so that they could complete surveys. The initial cohort completed the personality survey at six occasions, in 2008, 2009, 2011, 2013, 2014, and 2015. A second cohort completed the personality survey at five occasions, in 2010, 2011, 2013, 2014 and 2015. A third cohort completed the personality survey at four occasions, in 2012, 2013, 2014, and 2015. A fourth cohort completed the personality survey in 2014 and 2015. All cohorts 
completed each of the other surveys used in this study (work and schooling, health, income, and social integration and leisure) annually from 2008 to 2015.

\section{Participants}

\section{Retirees}

Of all participants who provided personality data, 2,197 responded yes to either of the questions "I have taken early retirement," or "I am a pensioner," and no to the question "I perform paid work," at one or more measurement occasions. These participants were then asked, “in what year/month did you stop working?” We selected the 859 participants who indicated that they stopped working within 60 months of the measurement occasion. To better isolate the temporal effect of retirement, we excluded 166 participants who indicated that they stopped working at multiple different dates. We further excluded 3 participants who indicated that they retired but were younger than 50 years old ${ }^{1}$. Thus, our final retirees sample included 690 participants who completed 1,916 personality questionnaires in total (Wave $1 \mathrm{~N}=690$, Wave 2 $\mathrm{N}=533$, Wave $3 \mathrm{~N}=367$, Wave $4 \mathrm{~N}=209$, Wave $5 \mathrm{~N}=103$, Wave $6 \mathrm{~N}=14$ ). These participants ranged in age from 51-81 years $(M=64.41, S D=3.61$, median $=64)$.

\section{Non-retirees}

A total of 8,251 participants who provided personality data responded yes to "Have you ever performed paid work in the past" and no to both "I have taken early retirement" and "I am a pensioner” across all measurement occasions. We created a comparison group of non-retirees from this pool using the technique of propensity-score matching. Specifically, we estimated propensity to retire from 22 demographic and health variables (see online supplemental materials

${ }^{1}$ We excluded these participants, ages 35, 36, and 38 at first measurement, because they were far younger than the other retirees in the sample. Results do not differ when including these participants in analyses. 
and Table 1). Propensity score matching techniques currently require complete data, so we used the R package mice (Royston \& White, 2011) to impute missing scores. We removed these imputed scores for all other analyses. Using the R package MatchIt (Ho, Imai, King, \& Stuart, 2006), we then conducted a logistic regression where participants' retirement status was predicted by these 22 variables and selected the non-retirees who were most similar in retirement propensity to those in the retirement group. To maximize the size of this propensity-scorematched sample, we matched each retiree to the four most similar non-retirees, with replacement. To ensure that matches were sufficiently similar to retirees, we pruned matches with a caliper distance of .2 or greater (cf. Thoemmes \& Kim, 2011). Thus, our final non-retirees sample was composed of 532 participants who completed 1,282 personality questionnaires in total. (Wave 1 $\mathrm{N}=$ 532, Wave $2 \mathrm{~N}=303$, Wave $3 \mathrm{~N}=$ 209, Wave $4 \mathrm{~N}=138$, Wave $5 \mathrm{~N}=83$, Wave $6 \mathrm{~N}=17$ ). These participants ranged in age from $17-90$ years $(M=59.22, S D=6.92$, median $=60)$. We illustrate the extent to which covariate match improves after propensity scoring in Table 1 . In most cases, especially for age, the match has been substantially improved.

\section{Measures}

\section{Big Five Personality Traits}

Big Five personality traits were assessed using the IPIP version of the Big-Five inventory (Goldberg, 1992; scales are publicly available at dataarchive.lissdata.nl/study_units/view/15). Each trait was measured by 10 questions, with responses measured on a 5-point Likert scale, ranging from 1 (very inaccurate) to 5 (very accurate). At wave 1 , the alpha reliability of each scale, pooled across retiree and non-retiree samples, was .75 for openness to experience, .75 for conscientiousness, .83 for extraversion, .76 for agreeableness, and .86 for emotional stability. More detailed information on alpha reliabilities for the entire LISS sample at all measurement 
waves can be found in Schwaba and Bleidorn (2017). This research has shown that these scales demonstrate measurement invariance across time and across age groups. To facilitate interpretation, we standardized scores using the grand mean of both groups to a mean of 0 and a standard deviation of 1 .

\section{Moderator variables}

We examined the moderating effects of two time-invariant covariates: participant's biological sex ( 1 = male, 2 = female) and early retirement (I have taken early retirement, $0=$ no, $1=$ yes) and eleven time-varying covariates: age, time spent volunteering (Considered all together, how much time do you spend on voluntary work per week, on average? (including hours that you possibly spend on informal care) 0 - 112; we omitted 19 responses where participants indicated they volunteered 16 or more hours per day; these extreme values may reflect constant caregiving rather than volunteering), subjective health (How would you describe your health, generally speaking? 1 = poor -5 = excellent), days per week performing strenuous physical activities (If you look back on the last 7 days, on how many of those days did you perform a strenuous physical activity such as lifting heavy loads, digging, aerobics or cycling? If you did not perform any strenuous physical activity, enter zero. 0- 7), social connectedness (a composite of six items; sample question: there are enough people to whom I feel closely connected 1 = yes $-3=$ no; reverse scored; alpha $=.77$ ), financial hardship (How easy is it for you to live off your current income? 0 = very hard - 10 = very easy; reverse scored), and each of the Big Five personality traits. Descriptive statistics and information on missing data for these variables is available in the online supplemental materials (Table S1).

\section{Statistical Analyses}

We conducted multilevel model analyses in R version 3.3.3 (R core team, 2017) using the 
package nlme (Pinhiero, Bates, DebRoy, \& Sarkar, 2014) and Maximum Likelihood estimation. We visualized results using the R package ggplot2 (Wickham, 2016). To compare fits of nested models, we used loglikelihood difference tests. To compare fits of non-nested models, we used the Bayesian Information Criterion (BIC; Duncan et al., 2013). R scripts that allow researchers with access to the LISS dataset to reproduce all results and graphs are available at osf.io/6frku/.

\section{Results}

\section{Development of Personality Traits Across the Transition to Retirement}

To examine personality trait development in retirees during the 60 months before and after they retired, we scaled time by months and centered participant's scores on the month in which they retired. We present the temporal density of data following this transformation in Table 2. We then estimated eight multilevel models in which measurement occasions were nested within participants over time (Figure 1). We selected the model that best fit the data for each personality trait.

For each personality trait, we first estimated model 1a, which suggests no change in personality across the transition to retirement. The sole parameter in this model is an intercept that is allowed to vary across participants (i.e. it is modeled as a random effect). We compared the fit of this model to the fit of model 2a, which includes both a random intercept and a second random parameter that estimates linear change across the study period. This model estimates a single change trajectory across the transition to retirement. We next estimated models $1 \mathrm{~b}$ and $2 \mathrm{~b}$, which add a second random intercept parameter to models 1a and 2a. These models estimate the extent to which there was change in personality occurring immediately after retirement. We next estimated models 1c and 2c, which add a second random slope parameter to models 1a and 1a. These models estimate the extent to which there was a change in the developmental trajectory 
after retirement. Finally, we estimated models $1 \mathrm{~d}$ and $2 \mathrm{~d}$, which estimate both change in intercept and a change in trajectory after retirement.

Model comparison tests indicated that openness development was best described by model 2d, conscientiousness development was best described by model 2a, extraversion development was best described by model 2a, agreeableness development was best described by model 2d, and emotional stability development was best described by model 2c. These results suggest that, for the traits of openness, agreeableness, and emotional stability, retirement was associated with changes in personality trait development. Immediately after retirement, people tended to become more open (standardized $\beta=.161, p=.002)$ and more agreeable $(\beta=.136, p=$ .031). Rates of change differed before and after retirement in the traits of openness $(\beta=-.005$ before, $\beta=-.003$ after), agreeableness ( $\beta=-.002$ before, $\beta=-.003$ after), and emotional stability ( $\beta=.003$ before, $\beta=.002$ after). For the traits of extraversion and conscientiousness, personality development was not affected by the transition to retirement. On average, people remained stable in their extraversion $(\beta=-.000, p=.51)$ and conscientiousness $(\beta=-.000, p=.59)$ both before and after they retired. We present the results of model comparison tests in Table 3 and parameter estimates of the best fitting models for each trait in Table $4^{2}$. We present graphs visualizing these results in Figure 2.

\section{Comparing Retirees and Workers}

We next examined the developmental trajectories of a propensity score matched sample

${ }^{2}$ These models also allowed us to examine quadratic developmental trajectories. Although, in some cases, quadratic models improved fit to the data, no quadratic fixed effects (for either the retiree or non-retiree groups) were significant at $p<.05$. This suggests that quadratic effects were driven primarily by interindividual differences in developmental trajectories. Including these parameters in models hampered our ability to compare developmental trajectories across groups and we did not have sufficient power to test for interactions with quadratic effects. Given these limitations, we restricted our analyses to linear effects. 
of non-retirees. For this group, we scaled time by months into study. To facilitate comparison with the retiree group, we centered time at month 18 , the median month of retirement in our retiree sample. We did not estimate piecewise models for this group. We present the parameter estimates for these models in Table 5 and figures visualizing these results in Figure 2.

We then compared the personality trait trajectories of retirees and non-retirees. These comparisons are typically conducted using multiple-groups comparison tests, which require the parameters of one model to be nested within the other (c.f. Duncan et al., 2013). Because we scaled time differently for retirees (distance from retirement) and non-retirees (time in study), these models were not nested, so we could not compare the groups using formal model testing procedures. We therefore conducted between-group comparisons by comparing 95\% confidence intervals around parameter values (Tables 4 and 5). These comparisons suggested that that, for the trait of agreeableness, development differed between retirees and non-retirees. Specifically, after retirement, retirees decreased more rapidly in agreeableness $(\beta=-.003$, 95\% CI [-.005, $.002]$ than non-retirees $(\beta=.000,95 \%$ CI [-.001, -.001]). For each of the other Big Five traits, retirees and non-retirees exhibited similar rates of change in personality.

\section{Individual Differences in Development Across the Transition to Retirement}

We next estimated the extent to which there were individual differences in personality trait change before and after retirement. To do this, we conducted model comparison tests in which we fixed each random effect to zero. We compared the fit of these constrained models to the fit of an unconstrained model. If the constrained model did not fit significantly worse, it would suggest that there are few individual differences in this parameter in the present sample.

Table 5 shows the results of these model comparison tests, which indicated that of a total of 15 parameters, only three could be treated as fixed effects: the change in openness intercept at 
retirement, the change in agreeableness intercept at retirement, and the change in emotional stability before retirement. All other parameters exhibited significant variance across participants.

\section{Moderators of Individual Differences in Development Across the Transition to Retirement}

For our final set of analyses, we examined covariates that might account for individual differences in development across the transition to retirement. For each trait, we tested a model in which each parameter with a significant random effect was moderated by 1$)$ age $(\mathrm{N}=677$ participants provided information on both age and personality), 2) early retirement ( $\mathrm{N}=690), 3)$ gender ( $N=677)$, 4) financial hardship $(\mathrm{N}=641)$, 5) volunteering $(\mathrm{N}=678), 6)$ subjective health $(\mathrm{N}=609), 7)$ strenuous physical activity $(\mathrm{N}=609), 8)$ perceived social connectedness $(\mathrm{N}$ = 614), and 9-12) each of the other four Big Five traits $(\mathrm{N}=690)$. To do this, we first selected the best-fitting model for each trait. We added the moderating covariate to this model as its own term, which allowed us to examine the covariate's associations with personality at $\mathrm{t}=0$, the month participants retired. To this model, we added parameters that estimated the interaction between the moderating covariate and each significant random effect. All covariates besides gender and early retirement were modeled as random effects to account for their within-person variance across time. To account for the number of model comparison tests being conducted, we set a threshold of $p<.01$ for statistical significance.

Results of these analyses suggested that age $(p s>.175)$ and early retirement $(p s>.198)$ were not significantly associated with any personality trait. With respect to gender, men were more emotionally stable at month of retirement $(\beta=0.174, p=.003)$ whereas women were more agreeable at month of retirement $(\beta=0.340, p<.001)$. Participants who experienced greater financial hardship at month of retirement were less emotionally stable $(\beta=-0.036, p=.001)$. 
People who volunteered more were more agreeable at month of retirement $(\beta=.007, p=.01)$. Physical activity $(p s>.09)$ and subjective health $(p s>.01)$ were not associated with any personality trait across the transition to retirement. Participants who were more socially connected at month of retirement tended to score higher on emotional stability $(\beta=0.246, p<$ $.001)$ and extraversion $(\beta=0.156, p<.001)$. Finally, participants who scored higher on each personality trait tended to score higher on all other personality traits at the time of retirement $(\beta$ s $>0.220$, ps < .006). We did not find significant associations between any covariate and any slope parameter $(p s>.01)$. We present the complete results of these analyses in the online supplementary materials (Table S2).

\section{Discussion}

Results of the present study suggested that the transition to retirement is characterized by change in the development of openness, agreeableness, and emotional stability, and continuity in conscientiousness and extraversion. Furthermore, there were significant individual differences in the development of each of these traits over the transition to retirement, but we were unable to identify any covariates that accounted for significant portions of this between-person variance in change. Next, we discuss the findings for each Big Five trait separately.

Retirees tended to decrease in openness as they approached their date of retirement $(d=$ .005 per month, 95\% CI [-.008, -.003]). This decrease is consistent with both normative agegraded changes in openness in late adulthood (Bleidorn \& Hopwood, 2017; Schwaba et al., 2017) and the developmental trajectory exhibited by the matched non-retirees group $(d=-.002$ per month, 95\% CI [-.003, -.001]). Immediately after their date of retirement, however, retirees exhibited a sudden increase in openness $(d=.161,95 \%$ CI $[.058, .214]$. These changes may be partly driven by changes in exploratory behavior (Schwaba et al., 2017). Immediately after 
retirement, people may be particularly likely to explore new activities, new roles, and new goals. Our results suggest that this exploratory period may be relatively short-lived, as retirees tended to resume decreases in openness in the years following retirement ( $d=-.003$ per month, 95\% CI $[-.005,-.002])$.

We did not find any associations between the transition to retirement and changes in conscientiousness. Retirees tended to remain stable in conscientiousness both before and after retirement ( $d=.000$ per month, 95\% CI [-.002, .000]), and the matched non-retirees group exhibited a similar trajectory ( $d=-.001$ per month, 95\% CI [-.002, .000]).

This result has important theoretical implications. The social investment principle (SIP; Roberts et al., 2005) states that people who increase their investment in work roles, especially in young adulthood, tend to become more conscientiousness (Hudson \& Roberts, 2016; Lüdtke, Roberts, Trautwein, \& Nagy, 2011). In this study, we examined the converse and found no effect, implying that relinquishing one's work role was not associated with decreases in conscientiousness. This finding suggests that role investment and divestment may have different effects on personality development at different life stages. In young adulthood, investing in work roles may be a critical ingredient that spurs increases in conscientiousness. People who fail to invest in a work role may not increase in conscientiousness to the extent that their peers do (Roberts, Walton, Bogg, \& Caspi, 2006). In late adulthood, after a person has built up their conscientiousness through many years of investment in a work role, age-graded role divestment in the form of retirement does not appear to be maladaptive. Framed in terms of Caspi and Moffitt's (1993) paradoxical theory of personality coherence, the press to behave in a conscientious manner may dissipate somewhat with retirement (e.g. retirees no longer must wake up on time for work), but it is not necessarily replaced by a press to behave in a less 
conscientious manner. Rather, some retirees may experience a press to behave more conscientiously, and others less conscientiously, resulting in substantial individual differences in conscientiousness development without change at the mean level.

It is important to note that we examined change in personality traits during a demographic role transition. However, we did not examine people’s subjective experiences when undergoing this transition. For example, some people may disengage from work long before they retire, and others may bring their work identity with them into retirement. Such subjective experiences may be better predictors of personality change (Lodi-Smith \& Roberts, 2007). To more directly test the propositions of SIP, future research should measure people's subjective experiences in the context of life events and personality trait change. Furthermore, null findings regarding retirement and conscientiousness development should be considered in the light of other longitudinal research on retirement and personality development, which has found associations between retirement and conscientiousness development (Löckenhoff et al., 2009; Specht et al., 2011). Specht and colleagues (2011) compared development in retirees to development in a diverse comparison group that included younger adults, while controlling for age. Löckenhoff and colleagues (2009) measured conscientiousness across two time points spaced nine years apart and found decreases localized to the conscientiousness facet of selfdiscipline. Differences between these studies and the present study may be due to these differences in study design. Indeed, when compared to populations that may be increasing in conscientiousness, or when examining the facet of self-discipline over long periods of time, retirement may be associated with decreases in conscientiousness.

We also did not find significant associations between the transition to retirement and changes in extraversion. Retirees tended to remain stable in extraversion both before and after 
retirement ( $d=-.001$ per month, 95\% CI [-.001, .000]), as did the matched group of non-retirees ( $d=-.001$ per month, 95\% CI [-.002, .000]). This is consistent with other studies on retirement and personality development (Mroczek \& Spiro, 2003; Löckenhoff et al., 2009; Specht et al., 2011). Across the transition to retirement, there may be few normative expectations regarding extraversion, resulting in individual differences in trait development and mean-level trait continuity (Moffitt \& Caspi, 1993).

We found changes in agreeableness development across the transition to retirement. Before retirement, people tended to remain stable in agreeableness ( $d=-.002$ per month, 95\% CI $[-.006, .000])$, as did the matched group of non-retirees $(d=-.000$ per month, 95\% CI [-.001, .001]). However, in the month after they retired, people tended to exhibit sudden increases in agreeableness $(d=.136,95 \%$ CI $[.013, .199])$. This sudden shift might reflect a contrast effect. For a brief period after they retire, people may be especially likely to compare the warm, positive post-retirement experiences they have among family and friends to the contentious, difficult experiences they had while working. Just as with changes in openness, however, we found that this disruption in agreeableness was rather short-lived. In the years after retirement, people tended to decrease in agreeableness ( $d=-.003$ per month, 95\% CI [-.005, -.002]), a finding that runs counter to the age-graded increases that are typically found in late adulthood (Roberts et al., 2006; Specht et al., 2011; Wortman et al., 2012) as well as the non-significant change trajectory exhibited by the matched non-retirees group ( $d=-.000$ per month, 95\% CI $[-.001, .001])$. This decrease may reflect a return to baseline after the post-retirement positive disruption in agreeableness. With time, the contrast between working life and retired life may dull, and retirees may generally return to the levels of agreeableness they exhibited before they retired. If this set-point hypothesis (Ormel, VonKoff, Jeronimus, \& Riese, 2017; Roberts, 2017) is correct, 
agreeableness decreases in retirement should be a relatively brief phenomenon, rather than a trend that persists throughout retirement. The findings of Löckenhoff and colleagues (2009), who found that retirement was associated with increases in agreeableness over a longer 9-year window, would support this interpretation. However, more research on the actual behavior, thoughts, and feelings experienced during the transition to retirement is needed to test the hypothesis that sudden increases in agreeableness after retirement are indeed driven by the perceived contrast between working and retired life.

For emotional stability, retirement was associated with a change in developmental trajectory. Before retirement, people tended to increase in emotional stability $(d=.003$ per month, 95\% CI [.001, .004]), consistent with both age-graded norms in older adulthood (Roberts et al., 2006; Specht et al., 2011; Wortman et al., 2012) and the developmental trend we observed in the matched comparison group ( $d=.003$ per month, 95\% CI [.002, .004]). We did not find significant individual differences in this developmental parameter, suggesting little deviance from the average trend of increasing emotional stability. After retirement, retirees exhibited a different, significant, developmental trajectory ( $d=.002$ per month, 95\% CI [.000, .003]). There were substantial individual differences in this developmental trajectory (greater than for all other slope parameters), suggesting that some people became much more emotionally stable in the months after they retired, and others became much less emotionally stable in the months after they retired. This is consistent with the notion that emotional stability development may be driven by affective responses to life events, which may be especially variable across the lifespan (Schwaba \& Bleidorn, 2017).

\section{Temporal Dynamics of Personality Change}

Past research on personality development and life events has generally focused on 
investigating which traits are associated with which events. Less attention has been paid to the temporal dynamics of change surrounding events (Luhmann et al., 2014). Indeed, it is largely unclear whether personality change in naturalistic (i.e. non-therapeutic) settings tends to occur gradually or rapidly (Roberts et al., 2017; Wrzus \& Roberts, 2017). In the present study, we found both rapid and gradual change in openness and agreeableness, and we found gradual change in emotional stability. Future research is needed to better understand when and why some trait change may occur rapidly while other change occurs gradually.

Scholars have recently speculated about the extent to which personality development follows an "elastic” pattern, where deviations from a baseline trait level following an event are counteracted throughout time (Ormel et al., 2017; Roberts, 2017). This pattern has been extensively investigated with regards to subjective well-being (c.f. Diener, Lucas, \& Scollon, 2006), but remains largely uninvestigated with respect to the Big Five personality traits (for an exception, see Kandler et al., 2010). The present set of results indicate that the development of agreeableness and openness following retirement may follow such an elastic pattern. Over time, retirement-related increases in agreeableness and openness may be counteracted and eventually accommodated into a person’s pre-retirement personality structure, potentially nullifying longterm effects of the event.

A final temporal question that this study investigated was whether personality tended to change in anticipation of retirement. We found that changes in personality development across the transition to retirement generally occurred after retirement, rather than in anticipation of the event. Specifically, change trajectories before retirement were generally consistent with agegraded norms and the developmental trajectories of the matched non-retirees group, while change trajectories after retirement often deviated from age-graded norms and development 
observed in the matched group of non-retirees.

Results of this study underscore the importance of measuring personality multiple times in proximity to an event. For example, we found that agreeableness showed different rates of change at different times across the transition to retirement. A short-term longitudinal study or a study with long intervals between assessment waves would have been unable to detect these nuanced changes in trait development. To avoid spurious results, future studies on personality trait development must carefully consider issues of time and timing in relation to life events (Luhmann et al., 2014).

\section{Limitations and Future Directions}

A major limitation of this research is that personality was assessed via self-report (c.f. Watson \& Humrichouse, 2006). Trajectories of other-reported personality change across the transition to retirement may follow different temporal patterns. Such discrepancies may have systematic underpinnings (Vazire, 2010) and would thus afford further insight into temporal dynamics of personality change. Longitudinal research that includes personality ratings from family members or peers is needed to better understand when and to what degree significant others detect personality trait changes in response to major life events.

Second, although propensity score matching techniques allow us to improve the quality of inferences drawn from observational data, we still cannot draw causal conclusions. In other words, we can conclude that retirement was associated with changes in development, but concluding that retirement caused changes in development using correlational data is a fundamentally unanswerable question.

Third, although we found significant individual differences in personality development across the transition to retirement, we were unable to identify any moderators that accounted for 
this variability. This does not mean that contextual moderators play no role in development across the transition to retirement. Rather, understanding the role that various contexts and resources play in the transition to retirement may require larger and more diverse samples.

Fourth, it is important to situate these findings in cultural, historical, and societal context. Associations between retirement and personality trait development may differ across time, cultures, and legal systems. Although this research was conducted in a sample representative of the population of the Netherlands, it may be difficult to generalize these results to groups for whom retirement may be a qualitatively different experience (Kim \& Moen, 2001). For example, in societies where retirement occurs later in life, associations between retirement and personality development may be more intertwined with aging processes. Additionally, in traditional societies where retirees are expected to assume grandparental roles, clearer role expectations in retirement may minimize individual differences in personality development (Caspi \& Moffitt, 1993).

Finally, the hierarchical nature of personality traits affords analysis on multiple levels. While the IPIP personality scales used in this study do not have a clear lower-order facet structure, future research that delves into facet-level development may uncover differential patterns of change and continuity within each trait, allowing for further theoretical refinement (cf. Löckenhoff et al., 2009).

\section{Conclusion}

A nuanced description of how personality traits change across the transition to retirement informs our understanding of both personality development in late adulthood and the temporal dynamics of personality change in response to major life events. We found that retirees exhibited sudden increases in openness and agreeableness in the month after retirement and then gradually declined in these traits. Retirees tended to increase in emotional stability before and after 
retirement. Retirees did not tend to change in conscientiousness or extraversion across the transition to retirement. More generally, we found that individuals differ substantially in the ways they prepare for, experience, and adapt to retirement.

Despite an accumulating body of research, our understanding of the environmental factors that explain population-level and individual-level personality development across the lifespan is far from complete. As a field, we know very little about the temporal dynamics of personality change. In addition to "which traits change,” future research on personality development and life events should also ask “when and how does trait change occur?” Doing so will allow us to more thoroughly understand the mechanisms underlying change and to better integrate findings across studies. 


\section{References}

Allemand, M., Zimprich, D., \& Hertzog, C. (2007). Cross-Sectional Age Differences and Longitudinal Age Changes of Personality in Middle Adulthood and Old Age. Journal of Personality, 75, 323-358.

Allemand, M., Zimprich, D., \& Martin, M. (2008). Long-term correlated change in personality traits in old age. Psychology and Aging, 23, 545

Allen, M. S., Magee, C. A., Vella, S. A., \& Laborde, S. (2017). Bidirectional associations between personality and physical activity in adulthood. Health Psychology, 36, 332.

Baltes, P. B. (1987). Theoretical propositions of life-span developmental psychology: On the dynamics between growth and decline. Developmental Psychology, 23, 611.

Nesselroade, J. R., \& Baltes, P. B. (Eds.). (1979). Longitudinal research in the study of behavior and development (p. 386). New York: Academic Press.

Bleidorn, W. (2012). Hitting the road to adulthood: Short-term personality development during a major life transition. Personality and Social Psychology Bulletin, 38, 1594-1608.

Bleidorn, W. (2015). What accounts for personality maturation in early adulthood?. Current Directions in Psychological Science, 24, 245-252.

Bleidorn, W., Buyukcan-Tetik, A., Schwaba, T., van Scheppingen, M. A., Denissen, J. J., \& Finkenauer, C. (2016). Stability and change in self-esteem during the transition to parenthood. Social Psychological and Personality Science, 7, 560-569.

Bleidorn, W., Hopwood, C. J., \& Lucas, R. E. (2016). Life Events and Personality Trait Change. Journal of Personality.

Carstensen, L. L., Fung, H. H., \& Charles, S. T. (2003). Socioemotional selectivity theory and the regulation of emotion in the second half of life. Motivation and Emotion, 27, 103-123. 
Caspi, A., \& Moffitt, T. E. (1993). When do individual differences matter? A paradoxical theory of personality coherence. Psychological Inquiry, 4, 247-271.

Caspi, A., \& Roberts, B. W. (2001). Personality development across the life course: The argument for change and continuity. Psychological Inquiry, 12, 49-66.

Coe, N. B., \& Zamarro, G. (2011). Retirement effects on health in Europe. Journal of Health Economics, 30, 77-86.

Costa, P. T., \& McCrae, R. R. (1980). Influence of extraversion and neuroticism on subjective well-being: happy and unhappy people. Journal of Personality and Social Psychology, 38, 668.

Diener, E., Lucas, R. E., \& Scollon, C. N. (2006). Beyond the hedonic treadmill: revising the adaptation theory of well-being. American Psychologist, 61, 305.

Digman, J. M. (1997). Higher-order factors of the Big Five. Journal of Personality and Social Psychology, 73, 1246.

Doss, B. D., Rhoades, G. K., Stanley, S. M., \& Markman, H. J. (2009). The effect of the transition to parenthood on relationship quality: an 8-year prospective study. Journal of Personality and Social Psychology, 96, 601.

Duncan, T. E., Duncan, S. C., \& Strycker, L. A. (2013). An introduction to latent variable growth curve modeling: Concepts, issues, and application. Routledge Academic.

Elder, G. H., Jr. (1995). The life course paradigm: Social change and individual development. In P. Moen, G. H. Elder, Jr., \& K. Lüscher (Eds.), Examining lives in context: Perspectives on the ecology of human development. 101-139.

Erikson, E. H. (1959). Identity and the life cycle: Selected papers. Psychological Issues, 1.

Fisher, J. C. (1993). A framework for describing developmental change among older 
adults. Adult Education Quarterly, 43, 76-89.

Freund, A. M., Nikitin, J., \& Ritter, J. O. (2009). Psychological consequences of longevity. Human Development, 52, 1-37.

Goldberg, L. R. (1992). The development of markers for the Big-Five factor structure. Psychological Assessment, 4, 26-42.

Han, S. K., \& Moen, P. (1999). Clocking out: Temporal patterning of retirement 1. American Journal of Sociology, 105, 191-236.

Ho, D., Imai, K., King, G., \& Stuart, E. (2006). MatchIt: MatchIt: Nonparametric Preprocessing for Parametric Casual Inference. R package version 2-2.

Hudson, N. W., \& Roberts, B. W. (2016). Social investment in work reliably predicts change in conscientiousness and agreeableness: A direct replication and extension of Hudson, Roberts, and Lodi-Smith (2012). Journal of Research in Personality, 60, 12-23.

Jackson, J. J., Thoemmes, F., Jonkmann, K., Lüdtke, O., \& Trautwein, U. (2012). Military training and personality trait development: Does the military make the man, or does the man make the military?. Psychological Science, 23, 270-277.

John, O. P., Naumann, L. P., \& Soto, C. J. (2008). Paradigm shift to the integrative big five trait taxonomy. In O. P. John, R. W. Robins, \& L. A. Pervin (Eds.), Handbook of personality: Theory and research, 3, 114-158.

Judge, T. A., Livingston, B. A., \& Hurst, C. (2012). Do nice guys—and gals—really finish last? The joint effects of sex and agreeableness on income. Journal of Personality and Social Psychology, 102(2), 390.

Kandler, C., Bleidorn, W., Riemann, R., Spinath, F. M., Thiel, W., \& Angleitner, A. (2010). Sources of cumulative continuity in personality: A longitudinal multiple-rater twin 
study. Journal of Personality and Social Psychology, 98, 995.

Kim, J. E., \& Moen, P. (2001). Is retirement good or bad for subjective well-being?. Current Directions in Psychological Science, 10, 83-86.

Löckenhoff, C. E., Terracciano, A., \& Costa Jr, P. T. (2009). Five-factor model personality traits and the retirement transition: longitudinal and cross-sectional associations. Psychology and Aging, 24, 722.

Lodi-Smith, J., \& Roberts, B. W. (2007). Social investment and personality: A meta-analysis of the relationship of personality traits to investment in work, family, religion, and volunteerism. Personality and Social Psychology Review, 11, 68-86.

Lüdtke, O., Roberts, B. W., Trautwein, U., \& Nagy, G. (2011). A random walk down university avenue: life paths, life events, and personality trait change at the transition to university life. Journal of Personality and Social Psychology, 101, 620.

Luhmann, M., Orth, U., Specht, J., Kandler, C., \& Lucas, R. E. (2014). Studying changes in life circumstances and personality: It's about time. European Journal of Personality, 28, 256266.

McAdams, D. P., de St Aubin, E. D., \& Logan, R. L. (1993). Generativity among young, midlife, and older adults. Psychology and aging, 8, 221.

Mike, A., Jackson, J. J., \& Oltmanns, T. F. (2014). The conscientious retiree: The relationship between conscientiousness, retirement, and volunteering. Journal of Research in Personality, 52, 68-77.

Mroczek, D. K., \& Spiro, A. (2003). Modeling intraindividual change in personality traits: Findings from the Normative Aging Study. The Journals of Gerontology Series B: Psychological Sciences and Social Sciences, 58, 153-165 
Mueller, S., Wagner, J., Voelkle, M. C., Smith, J., \& Gerstorf, D. (in press). The interplay of personality and functional health in old and very old age: Dynamic within-person interrelations across up to 13 years. Journal of Personality and Social Psychology.

Mueller, S., Wagner, J., Drewelies, J., Duezel, S., Eibich, P., Specht, J., ... \& Gerstorf, D. (2016). Personality development in old age relates to physical health and cognitive performance: Evidence from the Berlin Aging Study II. Journal of Research in Personality, 65, 94-108.

Nieß, C., \& Zacher, H. (2015). Openness to experience as a predictor and outcome of upward job changes into managerial and professional positions. PloS one, 10.

Neyer, F. J., \& Asendorpf, J. B. (2001). Personality-relationship transaction in young adulthood. Journal of Personality and Social Psychology, 81, 1190.

Neyer, F. J., \& Lehnart, J. (2007). Relationships matter in personality development: Evidence from an 8-year longitudinal study across young adulthood. Journal of Personality, 75, 535-568.

Ormel, J., VonKorff, M., Jeronimus, B. F., \& Riese, H. Set-point theory and personality development: Reconciliation of a paradox. In J. Specht (Ed.), Personality Development Across the Lifespan. Amsterdam, Academic Press.

Osborne, J. W. (2012). Psychological Effects of the Transition to Retirement/Effets psychologiques de la transition vers la retraite. Canadian Journal of Counselling and Psychotherapy, 46, 45.

Pinheiro, J., Bates, D., DebRoy, S., \& Sarkar, D. (2014). R Core Team (2014) nlme: linear and nonlinear mixed effects models. R package version 3.1-117.

Pundt, L. M., Wöhrmann, A. M., Deller, J., \& Shultz, K. S. (2015). Differential predictors of post-retirement life and work satisfaction. Journal of Managerial Psychology, 30, 216- 
231.

Reitz, A. K., Zimmermann, J., Hutteman, R., Specht, J., \& Neyer, F. J. (2014). How peers make a difference: The role of peer groups and peer relationships in personality development. European Journal of Personality, 28, 279-288.

Roberts, B. W. (2017). A Revised Sociogenomic Model of Personality. Journal of Personality.

Roberts, B. W., \& Mroczek, D. (2008). Personality trait change in adulthood. Current directions in psychological science, 17, 31-35.

Roberts, B. W., Walton, K. E., \& Viechtbauer, W. (2006). Patterns of mean-level change in personality traits across the life course: a meta-analysis of longitudinal studies. Psychological bulletin, 132, 1-25.

Roberts, B. W., Luo, J., Briley, D. A., Chow, P. I., Su, R., \& Hill, P. L. (2017). A Systematic Review of Personality Trait Change Through Intervention. Psychological Bulletin, 143, 117-141.

Roberts, B. W., Wood, D., \& Caspi, A. (2008). The development of personality traits in adulthood. In O. P. John, R. W. Robins, \& L. A. Pervin (Eds.), Handbook of personality: Theory and research, 3, 375-398.

Rosenberg, M. (1965). Society and the adolescent self-image. Princeton, NJ: Princeton University Press.

Royston, P., \& White, I. R. (2011). Multiple imputation by chained equations (MICE): implementation in Stata. Journal of Statistical Software, 45, 1-20.

Scherpenzeel, A., Das, J. W. M., Ester, P., \& Kaczmirek, L. (2010). 'True' longitudinal and probability-based internet panels: Evidence from the Netherlands. In M. Das, P. Ester, \& L. Kaczmirek (Eds.), Social and Behavioral Research and the Internet: Advances in 
applied methods and research strategies. New York: Routledge. 77-103.

Schwaba, T., \& Bleidorn, W. (2017). Individual differences in personality development across the adult lifespan. Journal of Personality.

Schwaba, T., Luhmann, M., Denissen, J. J. A., Chung, J. M., \& Bleidorn, W. (2017). Openness to Experience and Culture-Openness Transactions Across the Lifespan. Journal of Personality and Social Psychology.

Siegrist, J., Wahrendorf, M., Von Dem Knesebeck, O., Jürges, H., \& Börsch-Supan, A. (2007). Quality of work, well-being, and intended early retirement of older employees—baseline results from the SHARE Study. The European Journal of Public Health, 17, 62-68.

Son, J. and Wilson, J. (2011). Generativity and Volunteering. Sociological Forum, 26, 644-667.

Specht, J., Egloff, B., \& Schmukle, S. C. (2011). Stability and change of personality across the life course: the impact of age and major life events on mean-level and rank-order stability of the Big Five. Journal of personality and Social Psychology, 101, 862-882.

Specht, J., Bleidorn, W., Denissen, J. J., Hennecke, M., Hutteman, R., Kandler, C., ... \& Zimmermann, J. (2014). What drives adult personality development? A comparison of theoretical perspectives and empirical evidence. European Journal of Personality, 28, 216-230.

Stephan, Y., Sutin, A. R., \& Terracciano, A. (2014). Physical activity and personality development across adulthood and old age: Evidence from two longitudinal studies. Journal of Research in Personality, 49, 1-7.

Sutin, A. R., Zonderman, A. B., Ferrucci, L., \& Terracciano, A. (2013). Personality traits and chronic disease: Implications for adult personality development. The Journals of Gerontology Series B: Psychological Sciences and Social Sciences, 68, 912-920. 
Thoemmes, F. J., \& Kim, E. S. (2011). A systematic review of propensity score methods in the social sciences. Multivariate Behavioral Research, 46, 90-118.

Watson, D., \& Humrichouse, J. (2006). Personality development in emerging adulthood: integrating evidence from self-ratings and spouse ratings. Journal of Personality and Social Psychology, 91, 959-974

Wickham, H. (2016). ggplot2: Elegant graphics for data analysis. New York: Springer.

Wilt, J., \& Revelle, W. (2015). Affect, behaviour, cognition and desire in the Big Five: An analysis of item content and structure. European Journal of Personality, 29, 478-497.

Wrzus, C., \& Roberts, B. W. (2017). Processes of personality development in adulthood: The TESSERA framework. Personality and Social Psychology Review, 21, 253-277.

Vaidya, J. G., Gray, E. K., Haig, J., \& Watson, D. (2002). On the temporal stability of personality: evidence for differential stability and the role of life experiences. Journal of Personality and Social Psychology, 83, 1469-1484.

van Scheppingen, M. A., Jackson, J. J., Specht, J., Hutteman, R., Denissen, J. J., \& Bleidorn, W. (2016). Personality trait development during the transition to parenthood: A test of social investment theory. Social Psychological and Personality Science, 7, 452-462.

Vazire, S. (2010). Who knows what about a person? The self-other knowledge asymmetry (SOKA) model. Journal of Personality and Social Psychology, 98, 281-300.

Zimmermann, J., \& Neyer, F. J. (2013). Do we become a different person when hitting the road? Personality development of sojourners. Journal of Personality and Social Psychology, 105, 515-530. 
Table 1.

Mean covariate scores before and after propensity score matching $(N=8,941)$.

\begin{tabular}{|c|c|c|c|}
\hline Covariate & $\begin{array}{l}\text { Mean of } \\
\text { retirees }\end{array}$ & $\begin{array}{c}\text { Mean of } \\
\text { all non-retirees }\end{array}$ & $\begin{array}{c}\text { Mean of } \\
\text { propensity-score } \\
\text { Matched non-retirees }\end{array}$ \\
\hline $\begin{array}{l}\text { Propensity to retire based on } \\
\text { scores at first measurement }\end{array}$ & .65 & .03 & 0.65 \\
\hline Age & 63.60 & 37.58 & 63.76 \\
\hline $\begin{array}{l}\text { Number of household } \\
\text { members }\end{array}$ & 1.93 & 3.05 & 1.89 \\
\hline Cohabitation status & 0.75 & 0.78 & 0.73 \\
\hline Dwelling ruralness & 3.02 & 2.93 & 3.06 \\
\hline Education & 3.26 & 3.50 & 3.42 \\
\hline Financial hardship & 6.79 & 6.40 & 6.66 \\
\hline Openness to experience & 3.47 & 3.55 & 3.46 \\
\hline Conscientiousness & 3.80 & 3.64 & 3.74 \\
\hline Extraversion & 3.24 & 3.33 & 3.27 \\
\hline Agreeableness & 3.90 & 3.87 & 3.88 \\
\hline Emotional stability & 3.50 & 3.39 & 3.50 \\
\hline Self-esteem & 5.70 & 5.51 & 5.70 \\
\hline Subjective health & 3.13 & 3.27 & 3.15 \\
\hline Subjective changes in health & 2.98 & 3.07 & 3.04 \\
\hline Difficulty in physical activities & 1.75 & 1.59 & 1.78 \\
\hline Difficulty in social activities & 1.57 & 1.59 & 1.51 \\
\hline Difficulty in work activities & 1.65 & 1.73 & 1.58 \\
\hline Physical Activity & 1.19 & 1.30 & 1.18 \\
\hline Alcohol intake & 1.22 & 1.59 & 1.31 \\
\hline Flu vaccination & 1.45 & 1.89 & 1.42 \\
\hline Volunteer Time & 2.89 & 1.31 & 2.96 \\
\hline Social Connectedness & 2.66 & 2.66 & 2.67 \\
\hline
\end{tabular}


Table 2.

Density of data in retirees group ( $N=690,1,916$ observations)

\begin{tabular}{ccccccccccccc}
\hline Months after & -60 to & -49 to & -39 to & -29 to & -19 to & -9 to 0 & 1 to 10 & 11 to & 21 to & 31 to & 41 to & 51 to \\
retirement & -50 & -40 & -30 & -20 & -10 & & & 20 & 30 & 40 & 50 & 60 \\
$\mathrm{n}$ & 52 & 62 & 81 & 82 & 115 & 103 & 200 & 214 & 270 & 225 & 257 & 255 \\
\hline
\end{tabular}


Table 3.

Model comparison tests to determine the trajectory of personality development across the transition to retirement. ( $N=690,1,916$ observations)

\begin{tabular}{|c|c|c|c|c|c|c|c|c|c|c|}
\hline Trait & $\begin{array}{c}\text { Base } \\
\text { Model } \\
\end{array}$ & $\mathrm{df}$ & $\begin{array}{c}\text {-Log- } \\
\text { likelihood }\end{array}$ & $\mathrm{BIC}$ & $\begin{array}{l}\text { Nested } \\
\text { Model }\end{array}$ & $\mathrm{df}$ & $\begin{array}{c}\text {-Log- } \\
\text { likelihood }\end{array}$ & BIC & $\begin{array}{c}X^{2} \\
\text { diff. test }\end{array}$ & $\begin{array}{l}\text { BIC } \\
\text { diff. }\end{array}$ \\
\hline \multirow[t]{7}{*}{$\mathrm{O}$} & $1 \mathrm{a}$ & 3 & 580.56 & - & $2 a$ & 6 & 561.06 & - & $39.00 * * *$ & - \\
\hline & $2 a$ & 6 & 561.06 & - & $2 b$ & 10 & 553.15 & - & $15.83^{* *}$ & - \\
\hline & $2 b$ & 10 & 553.15 & - & $1 b$ & 6 & 573.66 & - & $-41.02 * * *$ & - \\
\hline & $2 b$ & 10 & - & 1181.88 & $2 c$ & 10 & - & 1183.83 & - & -1.95 \\
\hline & $2 b$ & 10 & 553.15 & - & 1c & 6 & 563.69 & - & $-21.08 * * *$ & - \\
\hline & $2 b$ & 10 & 553.15 & - & $2 d$ & 15 & 545.90 & - & $14.49 *$ & - \\
\hline & $2 d$ & 15 & 545.90 & - & $1 d$ & 10 & 556.41 & - & $-21.04 * * *$ & - \\
\hline \multirow[t]{7}{*}{$\mathrm{C}$} & $1 \mathrm{a}$ & 3 & 675.02 & - & $2 a$ & 6 & 675.02 & - & $47.77 * * *$ & - \\
\hline & $2 a$ & 6 & 675.02 & - & $2 b$ & 10 & 673.10 & - & 3.85 & - \\
\hline & $2 a$ & 6 & - & 1395.39 & $1 b$ & 6 & - & 1418.48 & - & -23.09 \\
\hline & $2 \mathrm{a}$ & 6 & 675.02 & - & 2c & 10 & 672.20 & - & 5.65 & - \\
\hline & $2 a$ & 6 & - & 1395.39 & 1c & 6 & - & 1408.84 & - & -13.45 \\
\hline & $2 \mathrm{a}$ & 6 & 675.02 & - & $2 d$ & 15 & 667.94 & - & 14.15 & - \\
\hline & $2 a$ & 6 & 675.02 & - & $1 d$ & 10 & 675.59 & - & -1.13 & - \\
\hline \multirow[t]{7}{*}{$\mathrm{E}$} & $1 \mathrm{a}$ & 3 & 939.28 & - & $2 a$ & 6 & 924.09 & - & $30.37 * * *$ & - \\
\hline & $2 a$ & 6 & 924.09 & - & $2 b$ & 10 & 921.52 & - & 5.14 & - \\
\hline & $2 \mathrm{a}$ & 6 & - & 1893.54 & $1 b$ & 6 & - & 1902.09 & - & -8.54 \\
\hline & $2 \mathrm{a}$ & 6 & 924.09 & - & $2 c$ & 10 & 920.28 & - & 7.63 & - \\
\hline & $2 \mathrm{a}$ & 6 & - & 1893.54 & 1c & 6 & - & 1910.00 & - & -16.46 \\
\hline & $2 \mathrm{a}$ & 6 & 924.09 & - & $2 d$ & 15 & 917.22 & - & 13.75 & - \\
\hline & $2 a$ & 6 & 924.09 & - & $1 d$ & 10 & 924.75 & - & -1.32 & - \\
\hline \multirow[t]{7}{*}{$\mathrm{A}$} & $1 \mathrm{a}$ & 3 & 707.94 & - & $2 a$ & 6 & 681.35 & - & $33.20 * * *$ & - \\
\hline & $2 a$ & 6 & 681.35 & - & $2 b$ & 10 & 685.70 & - & $-11.29 *$ & - \\
\hline & $2 b$ & 10 & 685.70 & - & $1 b$ & 6 & 705.33 & - & $-39.26 * * *$ & - \\
\hline & $2 b$ & 10 & - & 1446.99 & $2 c$ & 10 & - & 1443.00 & - & -3.99 \\
\hline & 2c & 10 & 683.71 & - & 1c & 6 & 696.58 & - & $-25.74 * * *$ & - \\
\hline & 2c & 10 & 683.71 & - & $2 d$ & 15 & 677.40 & - & $12.62 *$ & - \\
\hline & $2 d$ & 15 & 677.40 & - & $1 d$ & 10 & 693.61 & - & $-32.43 * * *$ & - \\
\hline \multirow[t]{7}{*}{$\mathrm{ES}$} & $1 \mathrm{a}$ & 3 & 1196.42 & - & $2 a$ & 6 & 1174.99 & - & $42.86 * * *$ & - \\
\hline & $2 a$ & 6 & 1174.99 & - & $2 b$ & 10 & 1172.92 & - & 4.14 & - \\
\hline & $2 a$ & 6 & - & 2395.33 & $1 b$ & 6 & - & 2420.95 & - & -25.62 \\
\hline & $2 \mathrm{a}$ & 6 & 1174.99 & - & 2c & 10 & 1168.45 & - & 13.08* & - \\
\hline & 2c & 10 & 1168.45 & - & 1c & 6 & 1173.76 & - & $-10.62 *$ & - \\
\hline & 2c & 10 & 1168.45 & - & $2 d$ & 15 & 1167.73 & - & 1.45 & - \\
\hline & $2 c$ & 10 & - & 2412.48 & $1 \mathrm{~d}$ & 10 & - & 2420.05 & - & -7.57 \\
\hline
\end{tabular}

Note. $\mathrm{O}=$ openness to experience. $\mathrm{C}=$ conscientiousness. $\mathrm{E}=$ extraversion. $\mathrm{A}=$ agreeableness. 
$\mathrm{ES}=$ emotional stability. $\mathrm{df}=$ degrees of freedom. $\mathrm{BIC}=$ Bayesian Information Criterion. In cases where models were nested, $X^{2}$ difference tests were used for comparison and $p<.05$ was used as the cutoff to determine the better fitting model. When models were not nested, BIC was used for comparison. All models were significantly misfit to the data at $p<.001$. $^{*}=p<.05$, $* *=p<.01, * * *=p<.001$. 
Table 4.

Parameter estimates for the best fitting development model for each personality trait across the transition to retirement ( $N=690,1,916$ observations).

\begin{tabular}{clrrrr}
\hline Trait & \multicolumn{1}{c}{ Parameter } & \multicolumn{1}{c}{$\beta$} & \multicolumn{1}{c}{$95 \%$ CI } & $p$ & $\begin{array}{c}\text { Standard deviation of } \\
\text { random effect }\end{array}$ \\
\hline $\mathrm{O}$ & Intercept & -0.110 & {$[-0.222,-0.053]$} & 0.053 & 0.891 \\
& Linear $\Delta$ before & $-0.005^{* *}$ & {$[-0.008,-0.003]$} & 0.002 & 0.007 \\
& Level $\Delta$ & $0.161^{* *}$ & {$[0.058,0.214]$} & 0.002 & 0.325 \\
& Linear $\Delta$ after & $-0.003^{* *}$ & {$[-0.005,-0.002]$} & 0.006 & 0.012 \\
$\mathrm{C}$ & Intercept & -0.004 & {$[-0.083,0.036]$} & 0.918 & 0.875 \\
& Linear $\Delta$ & 0.000 & {$[-0.002,0]$} & 0.593 & 0.008 \\
$\mathrm{E}$ & Intercept & -0.007 & {$[-0.082,0.031]$} & 0.854 & 0.875 \\
& Linear $\Delta$ & 0.000 & {$[-0.001,0]$} & 0.514 & 0.006 \\
$\mathrm{~A}$ & Intercept & -0.081 & {$[-0.215,-0.013]$} & 0.232 & 0.991 \\
& Linear $\Delta$ before & -0.002 & {$[0.006,0.000]$} & 0.254 & 0.016 \\
& Level $\Delta$ & $0.136^{*}$ & {$[0.013,0.199]$} & 0.031 & 0.381 \\
& Linear $\Delta$ after & $-0.003^{*}$ & {$[-0.005,-0.002]$} & 0.009 & 0.011 \\
ES & Intercept & -0.046 & {$[-0.138,0.001]$} & 0.326 & 0.930 \\
& Linear $\Delta$ before & $0.003^{*}$ & {$[0.001,0.004]$} & 0.014 & 0.004 \\
& Linear $\Delta$ after & $0.002^{*}$ & {$[0.000,0.003]$} & 0.046 & 0.011 \\
\hline
\end{tabular}

Note. $\mathrm{O}=$ openness to experience. $\mathrm{C}=$ conscientiousness. $\mathrm{E}=$ extraversion. $\mathrm{A}=$ agreeableness.

ES = emotional stability. Time is in units of months. $*=p<.05, * *=p<.01, * * *=p<.001$. 
Table 5.

Personality Development among propensity-score matched non-retirees $(N=532,1,282$ observations.)

\begin{tabular}{llrrrr}
\hline Trait & Parameter & $\beta$ & $95 \%$ CI & $p$ & $\begin{array}{c}\text { Standard deviation of } \\
\text { Random effect }\end{array}$ \\
\hline $\mathrm{O}$ & Intercept & $0.092^{*}$ & {$[0.002,0.138]$} & .047 & 0.936 \\
& Linear $\Delta$ & $-0.002^{* *}$ & {$[-0.003,-0.001]$} & .003 & 0.004 \\
$\mathrm{C}$ & Intercept & -0.032 & {$[-0.119,0.013]$} & .477 & 0.883 \\
& Linear $\Delta$ & -0.001 & {$[-0.002,0.000]$} & .463 & 0.006 \\
$\mathrm{E}$ & Intercept & 0.079 & {$[-0.010,0.125]$} & .081 & 0.946 \\
& Linear $\Delta$ & -0.001 & {$[-0.002,0.000]$} & .311 & 0.005 \\
$\mathrm{~A}$ & Intercept & 0.051 & {$[-0.041,0.097]$} & .277 & 0.917 \\
& Linear $\Delta$ & 0.000 & {$[-0.001,0.001]$} & .956 & 0.006 \\
$\mathrm{ES}$ & Intercept & $-0.109 *$ & {$[-0.196,-0.064]$} & .015 & 0.875 \\
& Linear $\Delta$ & $0.003^{* * *}$ & {$[0.002,0.004]$} & $<.001$ & 0.007 \\
\hline
\end{tabular}

Note. $\mathrm{O}=$ openness to experience. $\mathrm{C}=$ conscientiousness. $\mathrm{E}=$ extraversion. $\mathrm{A}=$ agreeableness.

$\mathrm{ES}=$ emotional stability. Time is in units of months. $*=p<.05 . * *=p<.01 . * * *=p<.001$. 
Table 6.

Model comparison tests to determine individual differences in personality development across the transition to retirement $(N=690,1,916$ observations $)$

\begin{tabular}{|c|c|c|c|c|c|c|c|}
\hline Trait & Base Model & $\mathrm{df}$ & $\begin{array}{l}\text {-Log- } \\
\text { likelihood }\end{array}$ & $\begin{array}{l}\text { Random } \\
\text { parameter } \\
\text { removed }\end{array}$ & $\mathrm{df}$ & $\begin{array}{l}\text {-Log- } \\
\text { likelihood }\end{array}$ & $\begin{array}{l}X^{2} \text { diff. } \\
\text { test }\end{array}$ \\
\hline \multirow[t]{3}{*}{$\mathrm{O}$} & $\begin{array}{l}\text { All parameters } \\
\text { random }\end{array}$ & 15 & 545.90 & Level $\Delta$ & 11 & 549.52 & 7.24 \\
\hline & Level $\Delta$ removed & 11 & 549.52 & $\Delta$ before & 8 & 556.75 & $14.45 * *$ \\
\hline & Level $\Delta$ removed & 11 & 549.52 & $\Delta$ after & 8 & 562.37 & $25.70 * * *$ \\
\hline $\mathrm{C}$ & $\begin{array}{l}\text { All parameters } \\
\text { random }\end{array}$ & 6 & 675.02 & Linear $\Delta$ & 4 & 698.69 & $47.34 * * *$ \\
\hline $\mathrm{E}$ & $\begin{array}{l}\text { All parameters } \\
\text { random }\end{array}$ & 6 & 924.09 & Linear $\Delta$ & 4 & 938.96 & $29.74 * * *$ \\
\hline \multirow[t]{3}{*}{ A } & $\begin{array}{l}\text { All parameters } \\
\text { random }\end{array}$ & 15 & 677.40 & Level $\Delta$ & 11 & 681.05 & 7.31 \\
\hline & Level $\Delta$ removed & 11 & 681.05 & $\Delta$ before & 8 & 694.05 & $25.99 * * *$ \\
\hline & Level $\Delta$ removed & 11 & 681.05 & $\Delta$ after & 8 & 692.25 & $22.39 * * *$ \\
\hline \multirow[t]{2}{*}{ ES } & $\begin{array}{l}\text { All parameters } \\
\text { random }\end{array}$ & 10 & 1168.45 & $\Delta$ before & 7 & 1169.79 & 2.68 \\
\hline & $\Delta$ before removed & 7 & 1169.79 & $\Delta$ after & 5 & 1186.19 & $32.80 * * *$ \\
\hline
\end{tabular}

Note. $\mathrm{O}=$ openness to experience. $\mathrm{C}=$ conscientiousness. $\mathrm{E}=$ extraversion. $\mathrm{A}=$ agreeableness.

$\mathrm{ES}=$ emotional stability. $* *=p<.01, * * *=p<.001$ 
Figure 1.

Eight Models That May Describe Development Across the Transition to Retirement

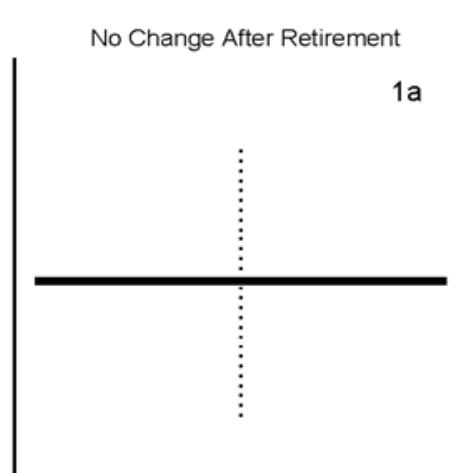

Sudden Change After Retirement

$1 \mathrm{~b}$

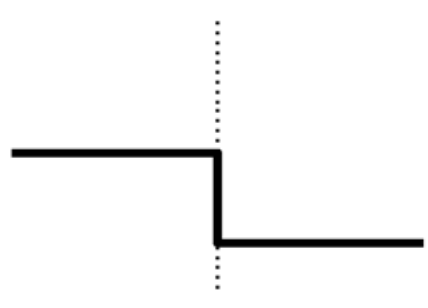

$2 a$

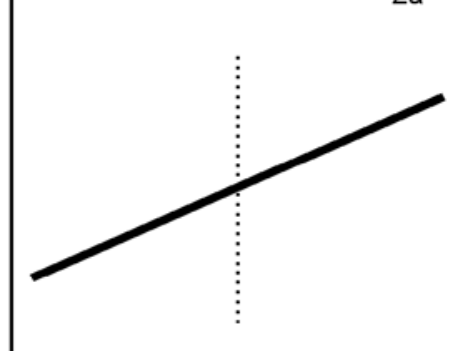

$2 b$
Gradual Change After Retirement

$1 \mathrm{c}$
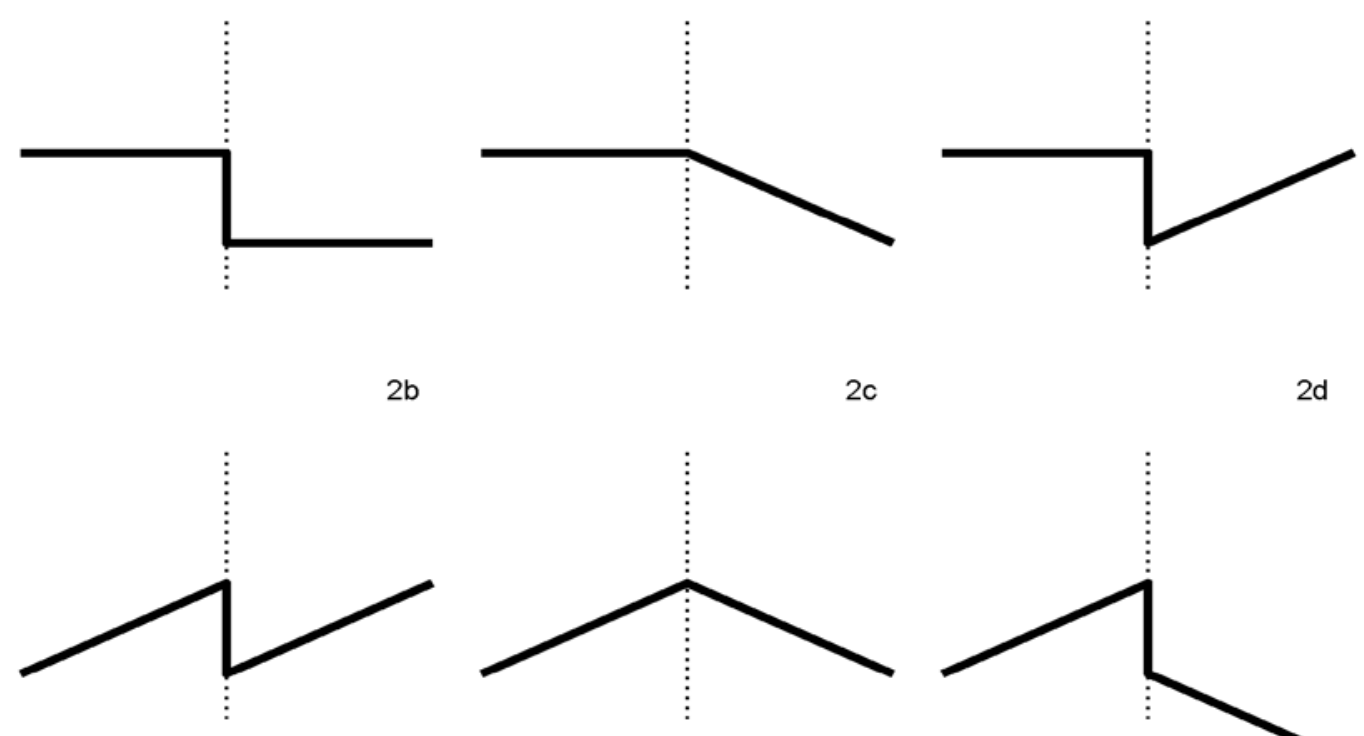

2c

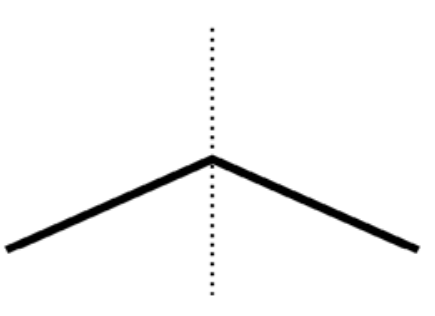

Note. Models adapted from Doss et al. (2009) and Bleidorn et al. (2016). 

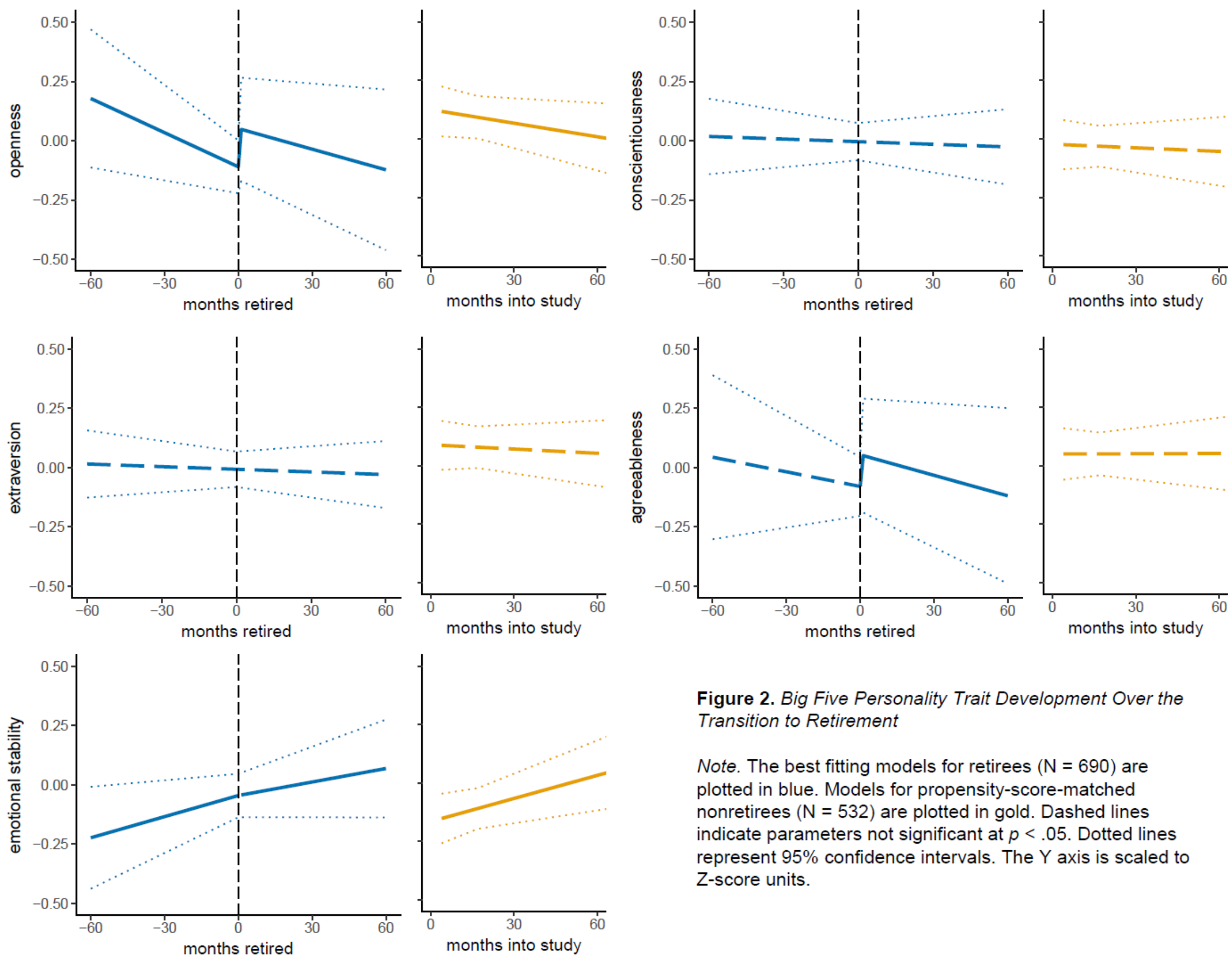

Figure 2. Big Five Personality Trait Development Over the Transition to Retirement

Note. The best fitting models for retirees $(\mathrm{N}=690)$ are plotted in blue. Models for propensity-score-matched nonretirees $(N=532)$ are plotted in gold. Dashed lines indicate parameters not significant at $p<.05$. Dotted lines represent $95 \%$ confidence intervals. The $Y$ axis is scaled to Z-score units. 